\title{
Probing the impact of protein and ligand preparation procedures on chemotype enrichment in structure-based virtual screening using DEKOIS 2.0 benchmark sets
}

Tamer M Ibrahim ${ }^{1 *}$, Matthias R Bauer ${ }^{1,2}$, Frank M Boeckler ${ }^{1}$

From 9th German Conference on Chemoinformatics

Fulda, Germany. 10-12 November 2013

Structure-based virtual screening techniques can help to identify new lead structures and complement other screening approaches in drug discovery. Prior to docking, the data (protein crystal structures and ligands) should be prepared with great attention to chemistryrelated molecular details. In all cases, a wide choice of commercially and non-commercially packages are available to perform such preparation schemes.

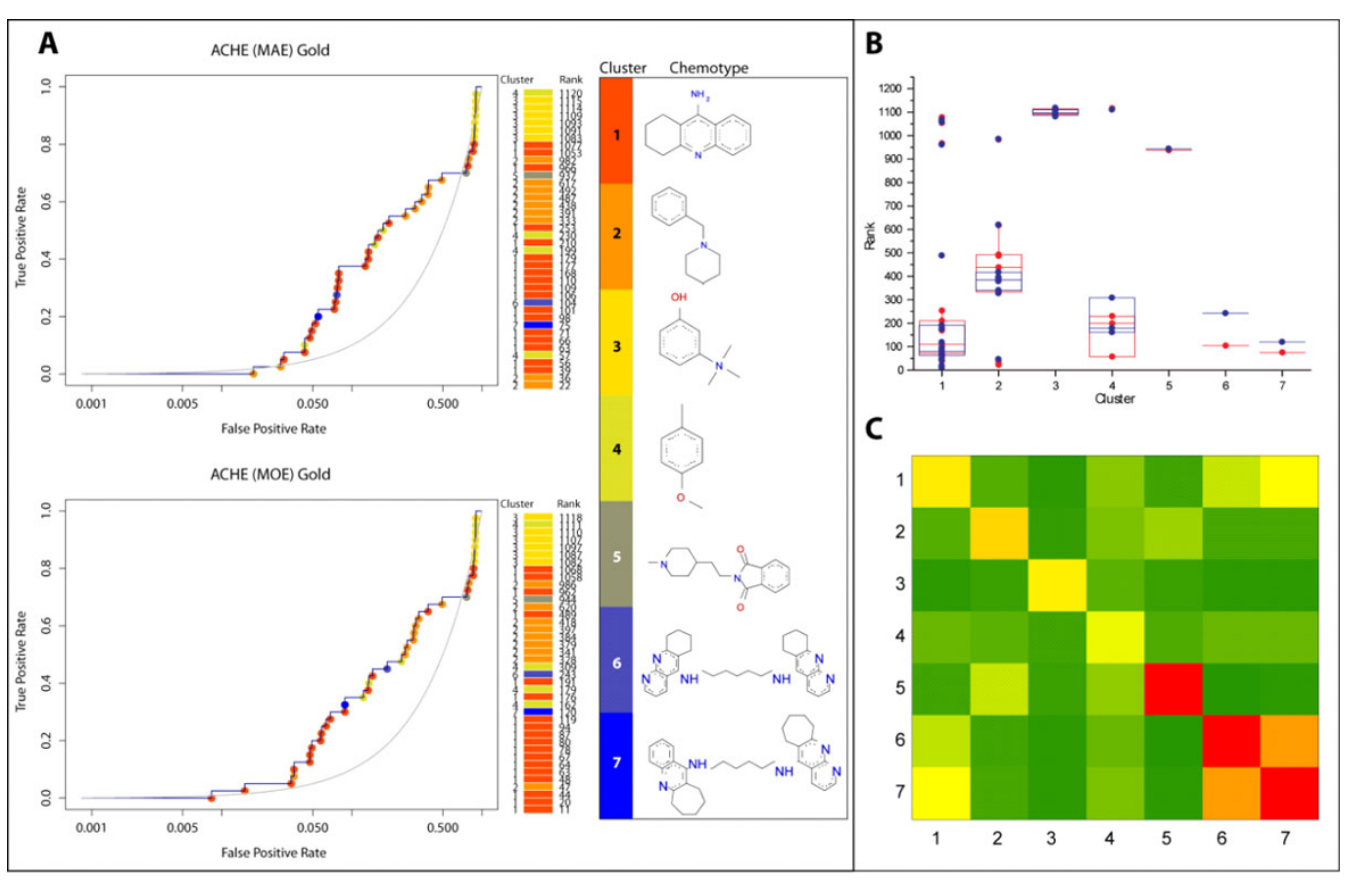

Figure 1

\footnotetext{
* Correspondence: tamer.abdelrehim@student.uni-tuebingen.de

'Lab. of Molecular Design \& Pharmaceutical Biophysics, University of

Tuebingen, Tuebingen, 72076, Germany

Full list of author information is available at the end of the article
} 
Using the DEKOIS 2.0 benchmark sets [1,2], we found differences in the respective virtual screening performance when employing different preparation schemes. We demonstrate how docking performance, particularly early enrichment, can be affected by these differences. To investigate these interesting results, we have developed an automated protocol to match and visualize ligand chemotype information in combination with the PROC profile obtained by docking. We can utilize this new tool to identify and highlight chemotype-specific behaviour, e.g. in dataset preparation. This can help to overcome chemistry-related issues in virtual screening.

\section{Authors' details}

${ }^{1}$ Lab. of Molecular Design \& Pharmaceutical Biophysics, University of Tuebingen, Tuebingen, 72076, Germany. ${ }^{2}$ MRC Laboratory of Molecular Biology, Cambridge CB2 OQH, UK.

Published: 11 March 2014

\section{References}

1. Vogel SM, Bauer MR, Boeckler FM: DEKOIS: demanding evaluation kits for objective in silico screening-a versatile tool for benchmarking docking programs and scoring functions. J Chem Inf Model 2011, 51(10):2650-2665.

2. Bauer MR, Ibrahim TM, Vogel SM, Boeckler FM: Evaluation and Optimization of Virtual Screening Workflows with DEKOIS 2.0 - A Public Library of Challenging Docking Benchmark Sets. J Chem Inf Model 2013, 53(6):1447-1462.

doi:10.1186/1758-2946-6-S1-P19

Cite this article as: Ibrahim et al:: Probing the impact of protein and ligand preparation procedures on chemotype enrichment in structurebased virtual screening using DEKOIS 2.0 benchmark sets. Journal of Cheminformatics 2014 6(Suppl 1):P19.

\section{Publish with ChemistryCentral and every} scientist can read your work free of charge

"Open access provides opportunities to our colleagues in other parts of the globe, by allowing anyone to view the content free of charge." W. Jeffery Hurst, The Hershey Company.

- available free of charge to the entire scientific community

- peer reviewed and published immediately upon acceptance

- cited in PubMed and archived on PubMed Central

- yours - you keep the copyright

Submit your manuscript here:

http://www.chemistrycentral.com/manuscript/<smiles>c1ccccc1</smiles> 